\title{
Catalytic and mechanistic studies into the epoxidation of styrenes using manganese complexes of structurally similar polyamine ligands.
}

Gennadiy Ilyashenko, Giorgio De Faveri, Thomas Follier, Rawan Al-Safadi, Majid Motevalli and Michael Watkinson*

The Joseph Priestley Building, School of Biological and Chemical Sciences, Queen Mary University of London, Mile End Road, London, E1 4NS, UK.

Emailm.watkinson@qmul.ac.uk

\begin{abstract}
:
Two structurally similar polyamine ligands (7 and 8) have been prepared, which differ only by the presence of either a secondary or tertiary nitrogen donor within their $\mathrm{N}_{5}$ donor set. The ligands, in combination with iron and manganese salts, have been screened for their efficacy as catalysts for the epoxidation of styrene, using both hydrogen peroxide and peracetic acid as oxidants. Clear differences in activity between the two systems were observed, with 7 proving most effective in the presence of $\mathrm{MnSO}_{4}$ with $\mathrm{H}_{2} \mathrm{O}_{2}$, whereas ligand 8 proved to be effective with $\mathrm{Mn}(\mathrm{OTf})_{2}, \mathrm{MnCl}_{2}$ and $\mathrm{Mn}\left(\mathrm{ClO}_{4}\right)_{2}$ using peracetic acid as the oxidant. A Hammett analysis of the initial rate kinetics of the optimal systems, combined with analysis by UV-vis spectroscopy, indicates that the small structural differences in the ligands elicit profound changes in the nature of the active species formed.
\end{abstract}

Keywords Epoxidation; Polyamine ligands; Manganese; Hydrogen peroxide; Kinetics.

\section{Introduction}

The oxidation of organic substrates is fundamental to contemporary synthetic chemistry and there continues to be a demand for new and efficient catalytic methods to effect regio- and stereoselective oxidative transformations. ${ }^{1}$ Within the very broad class of catalytic oxidative transformations, asymmetric epoxidation (AE) is an area which has received considerable attention due to the fact that a synthetically useful epoxide is generated containing up to two stereogenic centres from widely available alkene substrates. ${ }^{2}$ Since the seminal reports by Sharpless of the AE of allylic alcohols, ${ }^{3}$ and Jacobsen ${ }^{4}$ and Katsuki ${ }^{5}$ of the AE of certain 
unfunctionalised alkene substrates with manganese-salen complexes, a range of other highly effective and elegant metal-based and organocatalytic systems have been developed which are extremely effective for a wide range of substrates. ${ }^{6}$ Although some of these systems satisfy many of the increasingly demanding environmental and economic constraints of industry, some limitations persist. These include: the need for relatively high catalyst loadings; the environmentally non-benign solvents and oxidants used in some cases; difficulties in ligand synthesis and the ease of their modification in order to fine-tune catalyst activity and stereoselectivity, and relatively low turnover numbers and frequencies when compared to other catalytic systems (e.g. TONs for Noyori's asymmetric hydrogenation systems reach up to 2400 000, with TOFs similarly impressive $\mathrm{e}^{7}$ ). Furthermore, there is no generic catalyst that is capable of the $\mathrm{AE}$ of all alkene substrates. As a result there continues to be considerable interest in the development of new and improved catalytic systems.

Owing to their benign environmental character, low toxicity and cost, good atom economy and operational ease, much of the recent effort in this area has been focused on the activation of hydrogen peroxide or peracetic acid with complexes of both iron and manganese. ${ }^{6 b}$ Considerable success has been achieved with a range of aminopyridine-based ligands (1-6, Scheme 1), as a result of their ability to form catalytically active complexes with both manganese and iron. ${ }^{8}$ For example, manganese complexes of chiral ligands $\mathbf{1}$ and $\mathbf{2}$ have already shown promising activity in the epoxidation of the challenging bench-mark substrate styrene ( $83 \%$ yield, $15 \%$ ee and $85 \%$ yield, $43 \%$ ee respectively). ${ }^{8 \mathrm{e}}$ However, unwanted and competing decomposition of the hydrogen peroxide with these metals, via catalase-like pathways, can often be problematic and the enantioselectivity of these complexes is still modest; their further improvement being contingent on the chemist's ability to readily modify the ligand structure in order to allow additional tuning and optimisation of activity.

We became particularly interested in developing ligands which combine the chiral backbone derived from trans-diaminocyclohexane and the coordination environment of ligand $\mathbf{3}$, the complexes of which have already exhibited excellent reactivity in oxidation reactions. ${ }^{8 \mathrm{f}} \mathrm{We}$ postulated that ligands $\mathbf{7}$ and $\mathbf{8}$ (Scheme 1) would stabilise the putative high-valent manganese species expected to be the active oxidant, whilst also providing the potential to induce asymmetry as a result of the privileged nature of the diamine backbone. In addition the facile inclusion of secondary and tertiary amines in closely related ligands would allow their effects to be assessed. Herein we report our investigations and the unexpected results obtained during the catalytic screening and subsequent preliminary kinetic studies. 

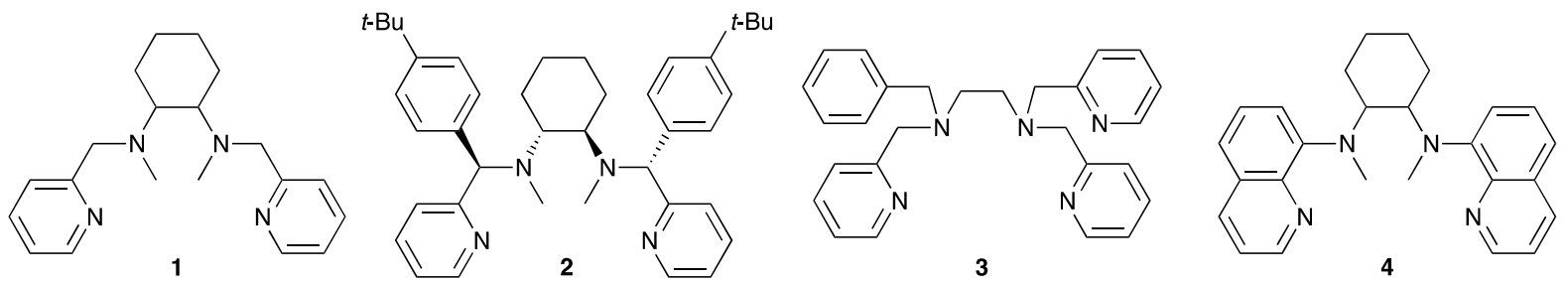

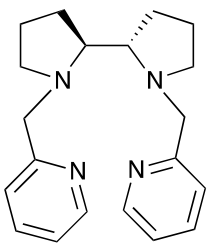

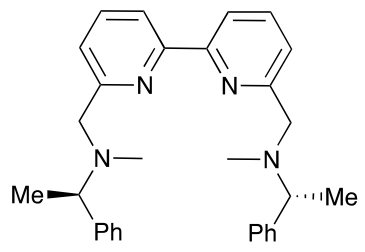

6

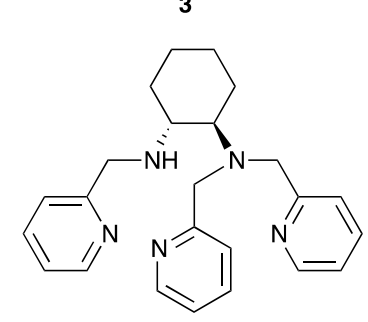

7

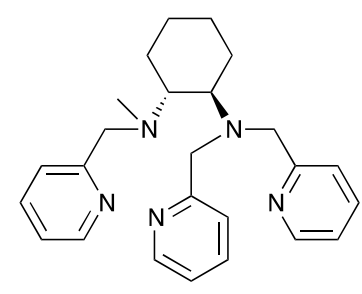

8

Scheme 1: Structure of previously synthesised aminopyridine ligands $\mathbf{1}-\mathbf{6}$ and ligands $\mathbf{7}$ and 8.

\section{Results and Discussions}

The desired ligands $\mathbf{7}$ and $\mathbf{8}$ were prepared in six steps in high enantiopurity and excellent yields (Scheme 2) by adapting reported methods. ${ }^{9}$
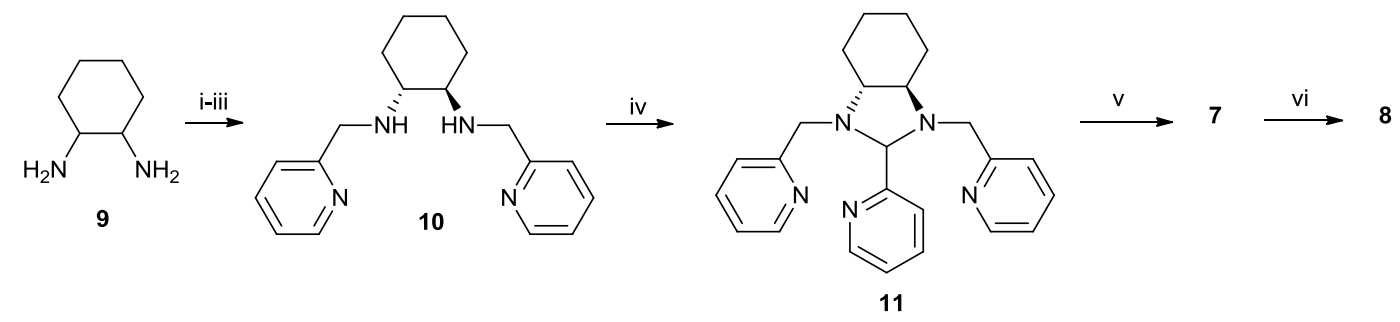

Scheme 2: Synthesis of ligands 7 and 8. Reagents and conditions: (i) L-tartaric acid, acetic acid, water; (ii) pyridine-2-carboxylaldehyde, $\mathrm{K}_{2} \mathrm{CO}_{3}$, EtOH, 90\%; (iii) $\mathrm{NaBH}_{4}, \mathrm{MeOH}, 88 \%$; (iv) pyridine-2-carboxylaldehyde, toluene, Dean-Stark, reflux, 88\%; (v) $\mathrm{NaBH}_{3}(\mathrm{CN}), \mathrm{MeOH}$, $87 \%$; (vi) $\mathrm{HCO}_{2} \mathrm{H}, \mathrm{CH}_{2} \mathrm{O}, \mathrm{H}_{2} \mathrm{O}, 93 \%$.

Amine 10 was readily obtained after the resolution of trans-1,2-diaminocyclohexane into diastereoisomeric tartrate salts, which underwent facile condensation with pyridine-2carboxyaldehyde followed by reduction of the imines with $\mathrm{NaBH}_{4}$ in excellent yield. With $\mathbf{1 0}$ in hand, addition of a further equivalent of pyridine-2-carboxylaldehyde gave aminal 11 which was reduced with $\mathrm{NaBH}_{3}(\mathrm{CN})$ to obtain ligand 7. Although it would be preferable to effect this transformation with other reducing agents, such as $\mathrm{NaBH}_{4}$, due to the potential toxicity and high cost of $\mathrm{NaBH}_{3}(\mathrm{CN})$, all of our efforts lead to either a substantial degradation of $\mathbf{1 1}$ or the reaction not proceeding to completion. Methylation of 7 was readily achieved using standard Eschweiler-Clarke conditions to produce ligand $\mathbf{8}$. 
With the ligands in hand we were able to carry out a preliminary screen for catalytic activity in the epoxidation of the challenging bench-mark substrate styrene, using both $\mathrm{H}_{2} \mathrm{O}_{2}$ and PAA, in combination with various metal salts (Scheme 3, Table 1). This was carried out according to previously developed procedures within our group, ${ }^{8 \mathrm{i}, 10}$ wherein both ligand and metal salt are mixed together for 30 minutes in $\mathrm{MeCN}$ at room temperature prior to the addition of the substrate. In all cases the complete disappearance of the ligand was confirmed by TLC prior to the addition of oxidant. The reaction was then initiated by the addition of the oxidant: (hydrogen peroxide in acetone was added to the reaction mixture at room temperature as has been widely used in related systems; ${ }^{6 b, 10}$ PAA was added to the reaction mixture which was cooled on ice to 3-4 ${ }^{\circ} \mathrm{C}$ ). Substrate conversion was monitored by collecting aliquots and analysing them by HPLC.

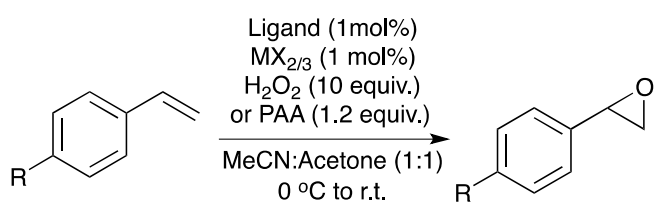

Scheme 3: Epoxidation of styrenes using in situ conditions.

Table 1: Epoxidation of styrene under various reaction conditions using ligands $\mathbf{7}$ and $\mathbf{8 .}$

\begin{tabular}{|c|c|c|c|c|c|c|c|c|}
\hline Entry & $\begin{array}{l}\text { Ligand } \\
(1 \mathrm{~mol} \%)\end{array}$ & $\begin{array}{l}\text { Metal Salt } \\
(1 \mathrm{~mol} \%)\end{array}$ & Oxidant & $\begin{array}{l}\text { Time } \\
(\mathbf{h})^{\mathrm{a}}\end{array}$ & $\begin{array}{l}\text { Conversion } \\
\%^{b}\end{array}$ & $\begin{array}{l}\text { Yield } \\
\%^{\text {b,c }}\end{array}$ & TON & $\begin{array}{l}\text { TOF } \\
\left(\min ^{-1}\right)\end{array}$ \\
\hline $1^{d}$ & 7 & $\mathrm{FeX}_{2 / 3}$ & $\mathrm{H}_{2} \mathrm{O}_{2} / \mathrm{PAA}$ & 8 & - & - & - & - \\
\hline $2^{d}$ & 8 & $\mathrm{FeX}_{2 / 3}$ & $\mathrm{H}_{2} \mathrm{O}_{2} / \mathrm{PAA}$ & 8 & - & - & - & - \\
\hline 3 & 7 & $\mathrm{MnSO}_{4}$ & PAA & 5 & - & - & - & - \\
\hline 4 & 7 & $\operatorname{Mn}(\mathrm{OTf})_{2}$ & PAA & 5 & - & - & - & - \\
\hline 5 & 7 & $\mathrm{MnCl}_{2}$ & PAA & 5 & - & - & - & - \\
\hline 6 & 7 & $\mathrm{Mn}\left(\mathrm{ClO}_{4}\right)_{2}$ & PAA & 5 & - & - & - & - \\
\hline 7 & 7 & $\mathrm{MnSO}_{4}$ & $\mathrm{H}_{2} \mathrm{O}_{2}$ & 5 & 100 & 78 & 100 & 0.33 \\
\hline 8 & 7 & $\operatorname{Mn}(\mathrm{OTf})_{2}$ & $\mathrm{H}_{2} \mathrm{O}_{2}$ & 8 & 51 & 13 & 51 & 0.11 \\
\hline 9 & 7 & $\mathrm{MnCl}_{2}$ & $\mathrm{H}_{2} \mathrm{O}_{2}$ & 8 & 65 & 5 & 65 & 0.13 \\
\hline 10 & 7 & $\mathrm{Mn}\left(\mathrm{ClO}_{4}\right)_{2}$ & $\mathrm{H}_{2} \mathrm{O}_{2}$ & 8 & 60 & 4 & 50 & 0.12 \\
\hline 11 & 8 & $\mathrm{MnSO}_{4}$ & $\mathrm{H}_{2} \mathrm{O}_{2}$ & 8 & 25 & 14 & 25 & 0.052 \\
\hline 12 & 8 & $\operatorname{Mn}(\mathrm{OTf})_{2}$ & $\mathrm{H}_{2} \mathrm{O}_{2}$ & 8 & 40 & 27 & 40 & 0.083 \\
\hline 13 & 8 & $\mathrm{MnCl}_{2}$ & $\mathrm{H}_{2} \mathrm{O}_{2}$ & 8 & 41 & 1 & 41 & 0.083 \\
\hline 14 & 8 & $\mathrm{Mn}\left(\mathrm{ClO}_{4}\right)_{2}$ & $\mathrm{H}_{2} \mathrm{O}_{2}$ & 8 & 37 & 2 & 37 & 0.077 \\
\hline 15 & 8 & $\operatorname{Mn}(\mathrm{OTf})_{2}$ & PAA & 1.5 & 100 & 93 & 100 & 1.11 \\
\hline 16 & 8 & $\mathrm{MnCl}_{2}$ & PAA & 1.5 & 100 & 74 & 100 & 1.11 \\
\hline 17 & 8 & $\mathrm{Mn}\left(\mathrm{ClO}_{4}\right)_{2}$ & PAA & 1.5 & 100 & 90 & 100 & 1.11 \\
\hline 18 & 8 & $\mathrm{MnSO}_{4}$ & PAA & 5 & 29 & 7 & 29 & 0.097 \\
\hline
\end{tabular}

a) Minimum time required for the reaction to reach its maximum conversion; b) the conversions and yields were calculated using HPLC; c) in cases when the yields were low 
compared to conversions a number of over-oxidation products were also observed, including 1phenylethyl-1,2-diol and benzaldehyde; d) Fe-salts used: $\mathrm{FeCl}_{3}$ (anhydrous), $\mathrm{Fe}\left(\mathrm{ClO}_{4}\right)_{3}$, $\mathrm{Fe}(\mathrm{OTf})_{2}, \mathrm{Fe}(\mathrm{OAc})_{2}, \mathrm{FeCl}_{2}$.

Despite a number of attempts, we did not observe any catalytic activity with the iron salts tested in combination with either ligand or oxidant (Table 1, entries 1 and 2) in contrast to other recently reported results. ${ }^{8 j}$ Also the combination of PAA as the oxidant with ligand 7 and a number of the manganese salts did not yield any activity (Table 1, entries 3-6). The combination of either ligands 7 or $\mathbf{8}$ with a range of manganese salts and $\mathrm{H}_{2} \mathrm{O}_{2}$ resulted in reasonable substrate conversions, although poor yields were observed in all cases with the exception of ligand 7, $\mathrm{MnSO}_{4}$ and $\mathrm{H}_{2} \mathrm{O}_{2}$ (Table 1, entry 7). Indeed, the catalytic activity of this combination $\left(\mathrm{TON}=100, \mathrm{TOF}=0.33 \mathrm{~min}^{-1}\right.$ ) is higher than that observed for Katsuki's salalenTi catalyst $\left(\mathrm{TON}=100, \mathrm{TOF}=1.16 \times 10^{-3} \mathrm{~min}^{-1}\right),{ }^{11}$ yet is lower than that of manganese complexes derived from triazacyclononane $\left(\mathrm{TON}=100, \mathrm{TOF}=2.22 \mathrm{~min}^{-1}\right.$ ) under similar reaction conditions. ${ }^{10}$ The considerable difference between the conversions and yields, particularly prevalent for both the perchlorate and chloride salts (Table 1, Entries 9, 10, 13 and 14) prompted a further analysis by HPLC and the ${ }^{1} \mathrm{H}$ NMR spectroscopy of the crude reaction mixtures. We identified that the low yields were a result of the over-oxidation of the styrene substrate, principally to form the 1-phenylethyl-1,2-diol and benzaldehyde.

Combination of ligand 8 with $\mathrm{Mn}(\mathrm{OTf})_{2} \mathrm{MnCl}_{2}$ and $\mathrm{Mn}\left(\mathrm{ClO}_{4}\right)_{2}$ and PAA (Table 1, entries 1517), resulted in complete conversion of styrene in 1.5 hours (e.g. for $\mathrm{Mn}(\mathrm{OTf})_{2}$ : TON $=100$, $\mathrm{TOF}=1.11 \mathrm{~min}^{-1}$ ) and produced the epoxide in excellent yields with only traces of overoxidation products being observed (Table 1, entries 15-17). This catalytic activity exhibited by this system is comparable to that observed with manganese complexes of ligand $\mathbf{2}$ under similar reaction conditions $\left(\mathrm{TON}=100, \mathrm{TOF}=1.11 \mathrm{~min}^{-1}\right) .{ }^{8 \mathrm{e}} \mathrm{In}$ contrast, $\mathrm{MnSO}_{4}$ proved relatively inactive in combination with 8 using PAA as the oxidant (Table 1, entry 18). Disappointingly, despite the high catalytic activity exhibited in several cases, only the combination of $\mathrm{MnSO}_{4}$ and 7 (system 1) and $\mathrm{Mn}(\mathrm{OTf})_{2}$ and 8 (system 2) ever produced non-racemic product, albeit with very low levels of asymmetric induction (11 and 15\% respectively). When compared to the state-of-art, systems such as Katsuki's salalen-Ti and ligand $\mathbf{5}$ derived catalysts which give ees of $93 \%^{11}$ and $43 \%^{8 \mathrm{~h}}$ respectively, the present system clearly exhibits an inferior level of enantioselectivity.

This moved us to investigate the reaction further and we carried out a series of blank experiments which have clearly shown that in order for the epoxidation to occur the reaction 
mixture must contain ligand, manganese salt, oxidant and the correct solvent ratio. Upon removal of the ligand from the reaction mixture only a very slow background oxidation was observed, which resulted in less than $20 \%$ conversion of substrate over a $48 \mathrm{~h}$ period, giving an intractable mixture of products.

A recent report by Browne et al. has shown that a decomposition of structurally similar ligand results in the formation of picolinic acid, which then react with manganese to form an effective epoxidation catalyst. ${ }^{12}$ Given the structural similarity of $\mathbf{7}$ and $\mathbf{8}$ to the ligands used by Browne et al., we were keen to eliminate such a possibility in our study. Fortunately, under the reaction conditions we have employed for our systems, picolinic acid proved to be inactive in the presence of the manganese salts which showed activity. Moreover, the exposure of $\mathbf{7}$ and $\mathbf{8}$ to hydrogen peroxide or PAA in acetone- $\mathrm{d}_{6}$ and subsequent analysis by ${ }^{1} \mathrm{H}$ NMR spectroscopy showed that within the catalytic reaction times (up to $8 \mathrm{~h}$ ) both ligands were stable and only after $18 \mathrm{~h}$ was some ligand degradation observed.

Finally we prepared authentic metal complexes of both ligands (vide infra) and showed that their activity was the same as the in situ formed complexes. We are thus confident that during the timeframe of the reaction that the conversions and yields observed are due to the ligandmetal complexes, rather than being due to decomposition products or free metal species. ${ }^{2 b}$

The synthesis of the authentic complexes was carried out by reacting the ligand with the desired manganese salt in acetonitrile according to a previously reported procedure, ${ }^{8 \mathrm{i}}$ and these were isolated in good to excellent yields as pale yellow or off-white powders (Table 2).

Table 2: Summary of manganese complexes synthesised and their magnetic moments measured by the Evan's NMR method. ${ }^{13}$

\begin{tabular}{lllll}
\hline Entry & Complex & Yield $(\boldsymbol{\%})$ & $\chi_{\mathbf{c}} / \mathbf{1 0}^{\mathbf{- 6}} \mathbf{c m}^{\mathbf{3}} \mathbf{g}^{\mathbf{- 1}}$ & $\mu_{\text {eff }}\left(\mu_{\mathbf{B}}\right)$ \\
\hline $\mathbf{1}$ & $\mathrm{Mn}(\mathbf{7}) \mathrm{SO}_{4}$ & 59 & 26.6 & 5.84 \\
$\mathbf{2}$ & $\mathrm{Mn}(\mathbf{7})\left(\mathrm{ClO}_{4}\right)_{2}$ & 82 & 22.5 & 5.87 \\
$\mathbf{3}$ & $\mathrm{Mn}(\mathbf{7}) \mathrm{OAc}_{2}$ & 79 & 25.7 & 5.86 \\
$\mathbf{4}$ & {$[\mathrm{Mn}(\mathbf{7}) \mathrm{Cl}] \mathrm{Cl}_{2} \mathrm{O}$} & 91 & 28.3 & 5.88 \\
$\mathbf{5}$ & $\mathrm{Mn}(\mathbf{7}) \mathrm{OTf}_{2}$ & 85 & 19.3 & 5.85 \\
$\mathbf{6}$ & $\mathrm{Mn}(\mathbf{8}) \mathrm{Cl}_{2}$ & 82 & 27.7 & 5.90 \\
$\mathbf{7}$ & $\mathrm{Mn}(\mathbf{8}) \mathrm{OTf}_{2}$ & 38 & 19.0 & 5.84 \\
\hline
\end{tabular}

The complexes were characterized by mass spectrometry, UV/vis and IR spectroscopies. As expected a slight shift in IR-bands attributable to the pyridine moieties were observed between 1650 and $1550 \mathrm{~cm}^{-1}$ which is indicative of coordination to the manganese centre. The UV/vis 
spectra showed absorbance bands due to the ligands and, as expected for the manganese(II) centres formulated in Table 2, no $\mathrm{d}$-d transitions. The formation of the complexes was supported by the HRMS with $[\mathrm{MnL}]^{+}$ions being observed for all complexes. The Evans' NMR method $^{13}$ was used to determine the magnetic susceptibilities of the complexes and the data obtained from these measurements (Table 2) was also consistent with the spin-only value expected for magnetically dilute manganese(II)- $\mathrm{d}^{5}$ complexes.

The reaction between ligand 7 and $\mathrm{MnCl}_{2} 4 \mathrm{H}_{2} \mathrm{O}$ afforded an off-white solid. Dissolution of this material in a mixture of MeCN/DCM followed by slow evaporation gave pale yellow crystals suitable for single crystal X-ray diffraction. The crystal structure of the complex is shown in Figure 2 and relevant bond lengths and angles are recorded in Table 5. This revealed the manganese centre to display a distorted octahedral geometry with one chloride ion bound directly to the manganese atom and the other chloride counter ion outside the primary coordination sphere. The Mn-N bond lengths are comparable to those previously reported for similar structures. ${ }^{14}$

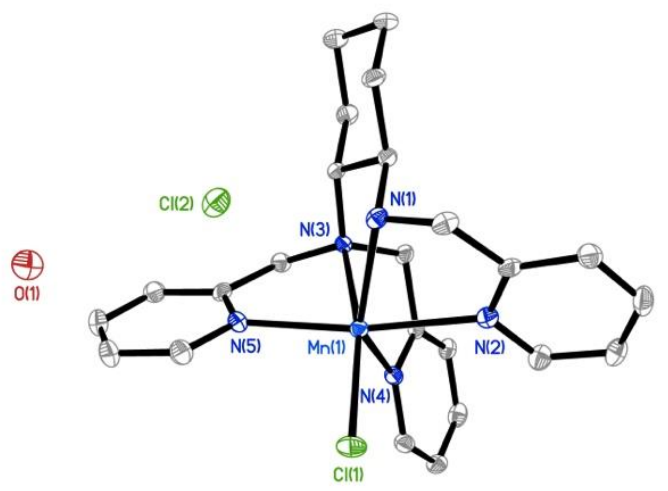

Figure 2:ORTEP plot showing the single crystal X-ray structure of complex $[\mathrm{Mn}(7) \mathrm{Cl}] \mathrm{Cl}^{\circ} \mathrm{H}_{2} \mathrm{O}$ with $50 \%$ thermal ellipsoids with hydrogen atoms omitted for clarity.

Table 5: Selected bond lengths and angles for $[\mathrm{Mn}(7) \mathrm{Cl}] \mathrm{Cl}^{\cdot} \mathrm{H}_{2} \mathrm{O}$ complex with esd's.

\begin{tabular}{ll|ll}
\hline & Bond length $(\AA)$ & & Bond angle $\left(^{\circ}\right)$ \\
\hline $\operatorname{Mn}(1)-\mathrm{N}(1)$ & $2.2441(17)$ & $\mathrm{N}(1)-\mathrm{Mn}(1)-\mathrm{N}(2)$ & $72.87(6)$ \\
$\mathrm{Mn}(1)-\mathrm{N}(2)$ & $2.3236(17)$ & $\mathrm{N}(1)-\mathrm{Mn}(1)-\mathrm{N}(3)$ & $77.57(6)$ \\
$\mathrm{Mn}(1)-\mathrm{N}(3)$ & $2.3440(17)$ & $\mathrm{N}(1)-\mathrm{Mn}(1)-\mathrm{N}(5)$ & $100.28(6)$ \\
$\mathrm{Mn}(1)-\mathrm{N}(4)$ & $2.2371(17)$ & $\mathrm{N}(1)-\mathrm{Mn}(1)-\mathrm{Cl}(1)$ & $116.82(5)$ \\
$\mathrm{Mn}(1)-\mathrm{N}(5)$ & $2.2598(17)$ & $\mathrm{N}(2)-\mathrm{Mn}(1)-\mathrm{Cl}(1)$ & $91.99(5)$ \\
$\mathrm{Mn}(1)-\mathrm{Cl}(1)$ & $2.4122(6)$ & $\mathrm{N}(3)-\mathrm{Mn}(1)-\mathrm{Cl}(1)$ & $163.42(4)$ \\
& & $\mathrm{N}(4)-\mathrm{Mn}(1)-\mathrm{Cl}(1)$ & $99.10(4)$ \\
& & $\mathrm{N}(5)-\mathrm{Mn}(1)-\mathrm{N}(3)$ & $72.95(6)$
\end{tabular}


Despite the lack of the enantioselectivity we decided to investigate the two most active systems with each oxidant more thoroughly i.e. ligand 7/ $\mathrm{MnSO}_{4} / \mathrm{H}_{2} \mathrm{O}_{2}$ (System 1) and ligand 8/ $\mathrm{Mn}(\mathrm{OTf})_{2} / \mathrm{PAA}$ (System 2) and screened them for activity with a range of $p$-substituted styrenes containing both electron donating and electron withdrawing groups (Table 2)

Table 2: Epoxidation of a range of $p$-substituted styrene substrates using the two catalytic systems.

\begin{tabular}{llllllll}
\hline Entry & $\begin{array}{l}\text { Catalytic } \\
\text { System }\end{array}$ & Substrate & $\begin{array}{l}\text { Time } \\
(\mathbf{h})^{\mathbf{a}}\end{array}$ & $\begin{array}{l}\text { Conversion } \\
\mathbf{\%}\end{array}$ & $\begin{array}{l}\text { Yield } \\
\mathbf{\%}\end{array}$ & TON $^{\mathbf{b}}$ & $\begin{array}{l}\text { TOF } \\
\mathbf{m i n}^{\mathbf{- 1}} \mathbf{)}\end{array}$ \\
\hline $\mathbf{1}$ & 1 & $p$-Methoxystyrene & 8 & 21 & - & 21 & 0.044 \\
$\mathbf{2}$ & 1 & $p$-Methylstyrene & 8 & 89 & 43 & 89 & 0.18 \\
$\mathbf{3}$ & 1 & Styrene & 5 & 100 & 78 & 100 & 0.33 \\
$\mathbf{4}$ & 1 & $p$-Fluorostyrene & 5 & 100 & 79 & 100 & 0.33 \\
$\mathbf{5}$ & 1 & $p$-Chlorostyrene & 5 & 100 & 75 & 100 & 0.33 \\
$\mathbf{6}$ & 1 & $p$-Bromostyrene & 6 & 100 & 39 & 100 & 0.27 \\
$\mathbf{7}$ & 1 & $p$-Nitrostyrene & 6 & 90 & 63 & 90 & 0.25 \\
$\mathbf{8}$ & 1 & $p$-Nitrilestyrene & 4 & 100 & 73 & 100 & 0.38 \\
$\mathbf{9}$ & 2 & $p$-Methoxystyrene & 1 & 100 & 10 & 100 & 1.67 \\
$\mathbf{1 0}$ & 2 & $p$-Methylstyrene & 2 & 100 & 45 & 100 & 0.83 \\
$\mathbf{1 1}$ & 2 & Styrene & 1.5 & 100 & 93 & 100 & 1.11 \\
$\mathbf{1 2}$ & 2 & $p$-Fluorostyrene & 1.5 & 100 & 98 & 100 & 1.11 \\
$\mathbf{1 3}$ & 2 & $p$-Chlorostyrene & 1.5 & 100 & 98 & 100 & 1.11 \\
$\mathbf{1 4}$ & 2 & $p$-Bromostyrene & 1.5 & 100 & 72 & 100 & 1.11 \\
$\mathbf{1 5}$ & 2 & $p$-Nitrostyrene & 1 & 100 & 43 & 100 & 1.67 \\
$\mathbf{1 6}$ & 2 & $p$-Nitrilestyrene & 0.25 & 100 & 58 & 100 & 6.67 \\
\hline
\end{tabular}

a) Minimum time required for the reaction to reach its maximum conversion; b) based on substrate conversions

The influence of the para-substituent on the reaction catalysed with System 1 quickly became apparent, with electron rich styrenes having the lowest conversions and yields (Table 2, entries 1 and 2), whilst other more electron deficient substrates deficient derivatives underwent complete conversion and gave the target epoxide in good yields, with the exception of $p$ bromostyrene (Table 2, entries $3-8$ ).

The reactions using System 2 produced broadly similar results. Although the overall conversion of styrenes was excellent in all cases, the yields of the epoxide products differed. Styrene, its para-fluoro- and chloro-derivatives were epoxidised in the highest yields (Table 
2, entries 11-13), whereas para-methyl-, nitro- and nitrile-styrene epoxides were formed in more modest yields, despite complete substrate conversion. Substituted styrene epoxides containing electron donating groups, such as methyl and methoxy are known to undergo hydrolysis in the presence of acids, ${ }^{15}$ hence while their decomposition under the reaction conditions is disappointing, it is not unexpected. It is also known that $p$-nitrostyrene oxide undergoes benzylic $\mathrm{C}-\mathrm{O}$ bond cleavage in the presence of acids, even though the electronwithdrawing nature of nitro- group should, in fact, decrease the rate of the reaction that results from the formation of positive charge at the benzylic position. ${ }^{15,16}$ Therefore it is reasonable to assume similar behaviour from $p$-nitrilestyrene oxide, hence explaining the lower than expected yields of the product. Analysis of the crude reaction mixtures by ${ }^{1} \mathrm{H}$ NMR-spectroscopy confirmed the formation of diols, further supporting this hypothesis. Finally, for reasons, which are not obvious at this stage, although $p$ - bromostyrene substrate was completely consumed by system 1, relatively little epoxide was observed.

In order to gain a further insight into the reaction pathway and understand if the oxygen transfer is a step-wise or concerted process we then investigated the epoxidation of $c i s$-stilbene. After subjecting the alkene to the oxidation under both sets of general conditions the crude reaction mixture was analysed by ${ }^{1} \mathrm{H}$ NMR spectroscopy, which clearly showed that the epoxide obtained had a trans-configuration. We therefore decided to investigate the initial rate kinetics of the epoxidation reactions using a Hammett analysis ${ }^{17}$ between the rate and $p$ substituents on styrene. ${ }^{10}$

Since at the start of the reaction the catalyst is present at the lowest concentration when compared to either the substrate or the oxidant and assuming that the oxygen transfer is the rate-determining step, it is appropriate to use a pseudo-first order approximation and obtain initial rates and initial rate constants (equation 1).

$$
\left.\left.\mathrm{R}_{\mathrm{i}}=\mathrm{ki} \text { [catalyst }\right] \text { where } \mathrm{ki}=\mathrm{k} \text { [substrate }\right](\text { Equation } 1)
$$

The initial rate constant, $\mathrm{ki}$, is proportional to the real rate constant, $\mathrm{k}$, hence the Hammett plots obtained with $\mathrm{ki}$ should be representative of those obtained using $\mathrm{k}$. Therefore, we focussed our efforts on obtaining the initial rates and ki values for both systems. All of the reactions were monitored by HPLC using anisole (and 1,2-dichlorobenzene for $p$-nitrilestyrene due to overlap in the HPLC trace) as the internal standard, which was calibrated simultaneously for each of the styrenes and its corresponding epoxide (see ESI for calibrations and representative reaction profiles). The reactions were run in triplicate in order to produce 
accurate and reproducible results and the data are presented in Table 3. The $\mathrm{k}_{\mathrm{i}}$-values were used to obtain Hammett plots, which graphically show the influence of the para-substituents on the reaction (Figure 1).

Table 3: Initial rates and $\mathrm{k}_{\mathrm{i}}$-values for each substrate catalysed by both systems.

\begin{tabular}{|c|c|c|c|c|}
\hline Entry & $\begin{array}{l}\text { Catalytic } \\
\text { System }\end{array}$ & Substrate & $\begin{array}{l}\mathbf{k}_{\mathbf{i}} \text { value } \\
\left(\mathrm{s}^{-1}\right)\end{array}$ & 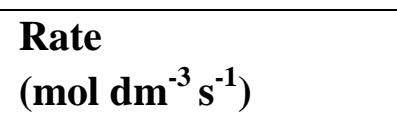 \\
\hline 1 & 1 & $p$-Methoxystyrene & $7.89 \times 10^{-5} \pm 3.57 \times 10^{-6}$ & $1.46 \times 10^{-8} \pm 6.06 \times 10^{-10}$ \\
\hline 2 & 1 & p-Methylstyrene & $9.29 \times 10^{-5} \pm 2.59 \times 10^{-6}$ & $1.72 \times 10^{-8} \pm 4.79 \times 10^{-10}$ \\
\hline 3 & 1 & Styrene & $1.17 \times 10^{-4} \pm 4.07 \times 10^{-6}$ & $2.16 \times 10^{-8} \pm 7.51 \times 10^{-9}$ \\
\hline 4 & 1 & $p$-Fluorostyrene & $1.32 \times 10^{-4} \pm 6.05 \times 10^{-5}$ & $2.44 \times 10^{-8} \pm 1.11 \times 10^{-9}$ \\
\hline 5 & 1 & $p$-Chlorostyrene & $1.40 \times 10^{-4} \pm 5.63 \times 10^{-6}$ & $2.59 \times 10^{-8} \pm 1.04 \times 10^{-9}$ \\
\hline 6 & 1 & $p$-Bromostyrene & $1.52 \times 10^{-4} \pm 1.25 \times 10^{-5}$ & $2.81 \times 10^{-8} \pm 2.31 \times 10^{-9}$ \\
\hline 7 & 1 & $p$-Nitrostyrene & $1.86 \times 10^{-4} \pm 1.76 \times 10^{-5}$ & $3.44 \times 10^{-8} \pm 3.26 \times 10^{-9}$ \\
\hline 8 & 1 & $p$-Nitrilestyrene & $3.29 \times 10^{-4} \pm 8.08 \times 10^{-6}$ & $6.09 \times 10^{-8} \pm 1.50 \times 10^{-9}$ \\
\hline 9 & 2 & $p$-Methoxystyrene & $1.85 \times 10^{-3} \pm 1.12 \times 10^{-4}$ & $3.41 \times 10^{-7} \pm 2.07 \times 10^{-8}$ \\
\hline 10 & 2 & $p$-Methylstyrene & $1.08 \times 10^{-3} \pm 7.08 \times 10^{-5}$ & $1.99 \times 10^{-7} \pm 1.44 \times 10^{-8}$ \\
\hline 11 & 2 & Styrene & $7.79 \times 10^{-4} \pm 2.13 \times 10^{-5}$ & $1.44 \times 10^{-7} \pm 3.93 \times 10^{-9}$ \\
\hline 12 & 2 & $p$-Fluorostyrene & $3.80 \times 10^{-4} \pm 1.94 \times 10^{-5}$ & $7.03 \times 10^{-8} \pm 3.58 \times 10^{-9}$ \\
\hline 13 & 2 & p-Chlorostyrene & $3.04 \times 10^{-4} \pm 2.73 \times 10^{-5}$ & $5.62 \times 10^{-8} \pm 5.05 \times 10^{-9}$ \\
\hline 14 & 2 & $p$-Bromostyrene & $5.81 \times 10^{-4} \pm 1.75 \times 10^{-5}$ & $1.07 \times 10^{-7} \pm 3.24 \times 10^{-9}$ \\
\hline 15 & 2 & $p$-Nitrostyrene & $0.0708 \pm 2.92 \times 10^{-3}$ & $1.31 \times 10^{-5} \pm 5.40 \times 10^{-6}$ \\
\hline 16 & 2 & $p$-Nitrilestyrene & $0.515 \pm 0.0209$ & $9.52 \times 10^{-5} \pm 3.87 \times 10^{-6}$ \\
\hline
\end{tabular}
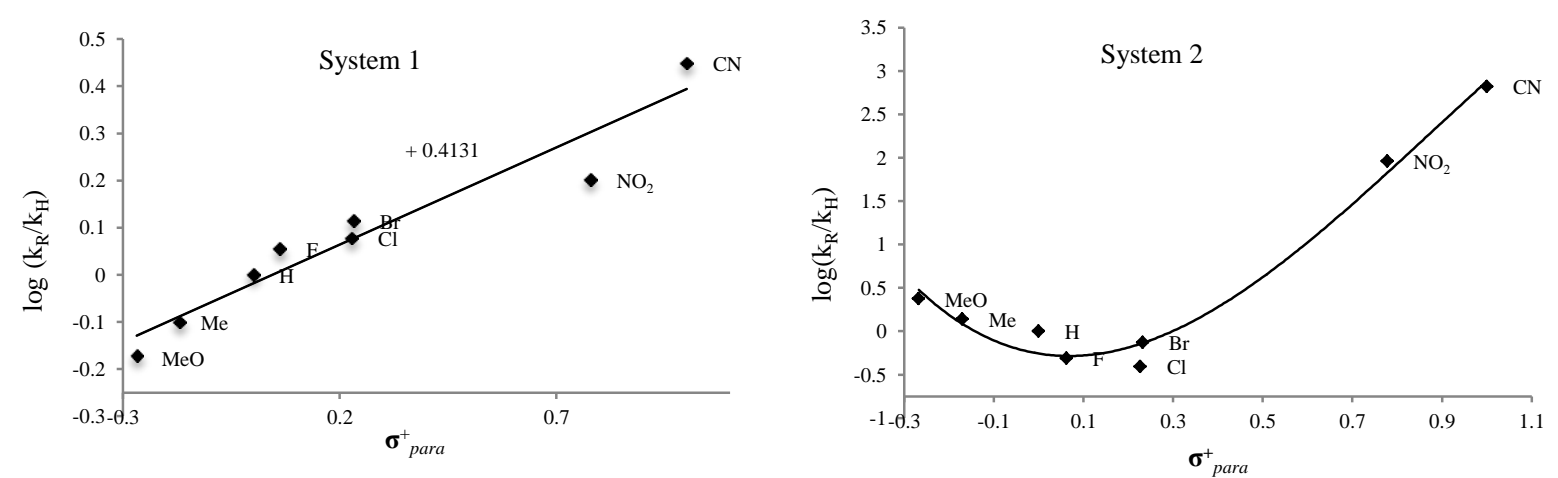

Figure 1: Hammett plots for both systems investigated.

Both systems exhibit unusual Hammett plots for manganese-containing epoxidation catalysts. ${ }^{10}$ The positive $\rho$-value $(+0.413)$ obtained in the case of ligand 7 and $\mathrm{MnSO}_{4}$ system indicates that the oxygen is delivered to styrene by the catalyst in a nucleophilic fashion. Thus, it seems unlikely that electrophilic $\mathrm{Mn}^{\mathrm{V}}=\mathrm{O}$ species, which are often invoked as key intermediates in the oxidation of organic substrates, are involved. The non-linearity in the Hammett plot obtained for ligand 8 and $\mathrm{Mn}(\mathrm{OTf})_{2}$ system is indicative of a fundamental 
change. ${ }^{18}$ With electron donating groups the catalyst exhibits typical electrophilic behaviour having significant $\rho$-value of -1.25 . However, with electron withdrawing groups the nucleophilic nature of the catalytic species takes over and dramatically influences the $\rho$-value $(+3.64)$.
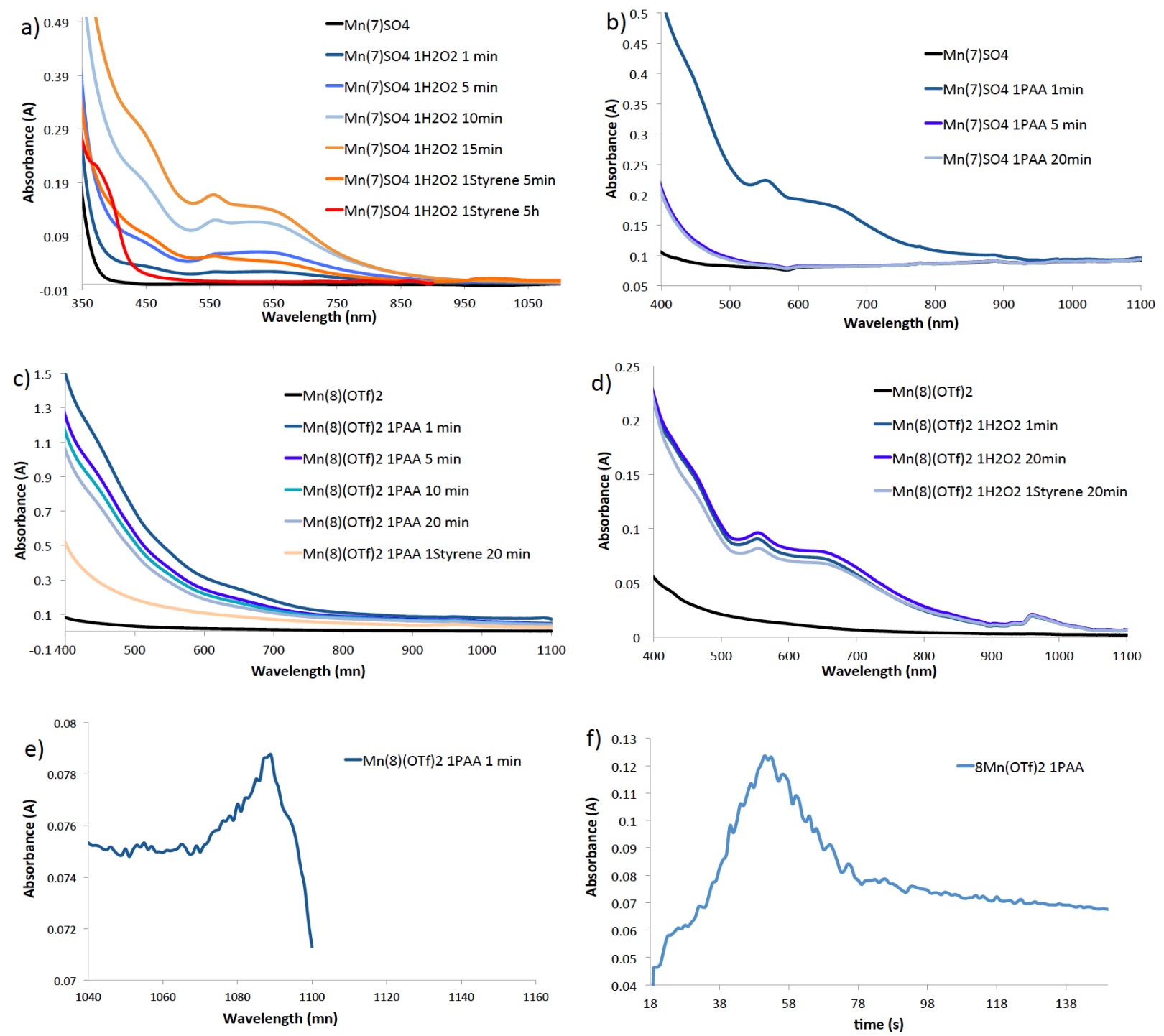

Figure 2: UV/vis spectra of catalytically active Systems 1 and 2 in the presence of $\mathrm{H}_{2} \mathrm{O}_{2}$ and PAA and substrate at various time intervals. a) $\mathrm{Mn}(7) \mathrm{SO}_{4}$ with $\mathrm{H}_{2} \mathrm{O}_{2}$; b) $\mathrm{Mn}(7) \mathrm{SO}_{4}$ with PAA; c) $\operatorname{Mn}(8)(\mathrm{OTf})_{2}$ with PAA; d) $\mathrm{Mn}(\mathbf{8})(\mathrm{OTf})_{2}$ with $\mathrm{H}_{2} \mathrm{O}_{2}$; e) expansion of Figure $2 \mathrm{c}$ showing the weak absorption band at $1090 \mathrm{~nm}$ for $\operatorname{Mn}(\mathbf{8})(\mathrm{OTf})_{2}$ with PAA; f) time-resolved UV-Vis at 1090 $\mathrm{nm}$ for $\mathrm{Mn}(\mathbf{8})(\mathrm{OTf})_{2}$ with PAA.

A brief examination of the active Systems 1 and 2 using UV-vis spectroscopy further highlighted differences between them. The stoichiometric reaction between $\mathrm{Mn}(7) \mathrm{SO}_{4}$ and $\mathrm{H}_{2} \mathrm{O}_{2}$ resulted in the build-up of a putative manganese(IV) species (Figure 2a). ${ }^{19,8 \mathrm{f}}$ The 
addition of 1 equivalent of styrene resulted in the rapid reduction in this species within 5 minutes and within 5 hours only manganese(III) species could be observed by UV-vis spectroscopy. Identical treatment of $\mathrm{Mn}(7) \mathrm{SO}_{4}$ with PAA also initially produced a similar band in the UV-vis spectrum (Figure 2b), however this combination of reagents is inactive in the epoxidation of styrene, and it also decomposed within 10 minutes. Any further addition of PAA to the reaction mixture resulted in rapid decomposition of the oxidant, with no change in the UV-vis spectra being observed.

Monitoring of the reaction between $\operatorname{Mn}(\mathbf{8})(\mathrm{OTf})_{2}$ and PAA using UV-vis spectroscopy did not provide any supporting evidence for the significant formation of the apparent manganese(IV) species observed with $\mathrm{Mn}(7) \mathrm{SO}_{4}$ (Figure 2c), although addition of the substrate to the species generated at 20 minutes resulted in very similar spectra. Interestingly, a weak absorption band at $1090 \mathrm{~nm}$ consistently appeared within the first minute of the addition of PAA and then rapidly disappeared. Similar bands have been previously reported in related complexes. ${ }^{20}$ In contrast, treating $\mathrm{Mn}(\mathbf{8})(\mathrm{OTf})_{2}$ with $\mathrm{H}_{2} \mathrm{O}_{2}$ (Figure 2d) appears to produce a similar manganese(IV) species to those observed with $\mathrm{Mn}(7) \mathrm{SO}_{4}$. Additionally another absorbance band at $966 \mathrm{~nm}$ is also present, ${ }^{19}$ however, the addition of styrene to the reaction mixture did not produce any distinct changes in the spectra. Figures $2 \mathrm{~b}$ and $2 \mathrm{~d}$ clearly show that while high oxidation state manganese-species can be obtained using both oxidants, they are not the same as the catalytically active species and appear to be unreactive.

In order to gain further insight into the different oxidative and catalytic behaviour exhibited by the manganese complexes of the two ligands, we decided to investigate the electrochemistry of the manganese centres. Due to the difference in solubility of $\mathrm{Mn}(7) \mathrm{SO}_{4}$ and $\mathrm{Mn}(\mathbf{8})(\mathrm{OTf})_{2}$ and possible counter ion exchange in the presence of supporting electrolytes with poorly coordinating anions we elected to use $\mathrm{Mn}(7) \mathrm{Cl}_{2}$ and $\mathrm{Mn}(\mathbf{8}) \mathrm{Cl}_{2}$ complexes.

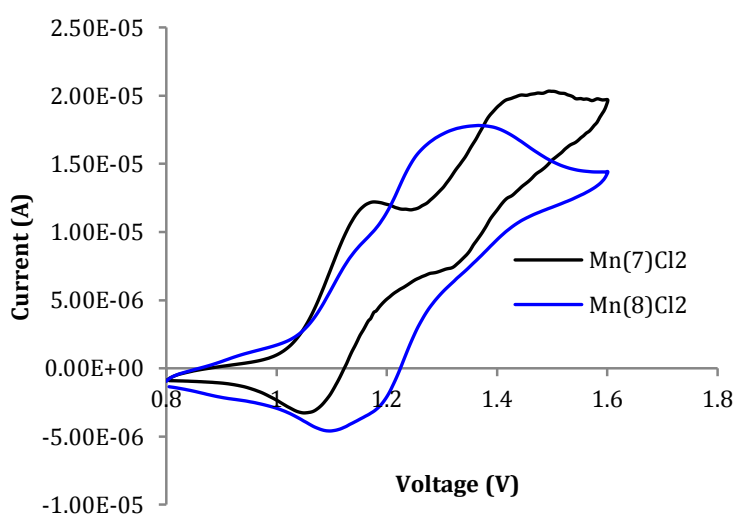


Figure 3: Cyclic voltammograms of $\mathrm{Mn}(7) \mathrm{Cl}_{2}$ and $\mathrm{Mn}(\mathbf{8}) \mathrm{Cl}_{2}$ in $\mathrm{MeCN}$ using $\left({ }^{t} \mathrm{Bu}_{4} \mathrm{~N}\right)\left(\mathrm{BF}_{4}\right)$ as electrolyte, $\mathrm{Pt}$-mesh counter electrode and $\mathrm{Ag} / \mathrm{AgCl}$ as reference electrode.

As expected, both complexes $\mathrm{Mn}(7) \mathrm{Cl}_{2}$ and $\mathrm{Mn}(\mathbf{8}) \mathrm{Cl}_{2}$ exhibit one electron oxidations at $E^{o}=$ +1.11 vs $\mathrm{Ag} / \mathrm{AgCl}$, which we assign to a manganeseII/III redox process, Figure $3 .^{21}$ The complex $\mathrm{Mn}(7) \mathrm{Cl}_{2}$ displays a further clear and reversible oxidative process $\mathrm{E}^{\mathrm{o}}=+1.37$ vs $\mathrm{Ag} / \mathrm{AgCl}$ with $\Delta \mathrm{E}=78 \mathrm{mV}$, which we tentatively assign to a manganese(III/IV) redox couple. Whilst a similar process also appears to occur for $\mathrm{Mn}(\mathbf{8}) \mathrm{Cl}_{2}$ with $\mathrm{E}^{\mathrm{o}}=+1.13$ vs $\mathrm{Ag} / \mathrm{AgCl}$ with $\Delta \mathrm{E}=64 \mathrm{mV}$, the wave is much broader and rather ill-defined. Nonetheless, this indicates that overall the formation of higher valent manganese species appears to be a less demanding process for $\mathrm{Mn}(\mathbf{8}) \mathrm{Cl}_{2}$.

Whilst high valent $\mathrm{Mn}^{\mathrm{V}}=\mathrm{O}$ have long been recognised as active catalysts, ${ }^{22,1}$ recently alternative high valent $\mathrm{Mn}^{\mathrm{IV}}=\mathrm{O}$ species have also emerged as catalytically competent species. ${ }^{8 \mathrm{f}}$ Studies have revealed subtle differences in reactivity of these species not only in their rates of reaction, but also in the way the actual oxidation reaction occurs i.e. concerted oxygen transfer $v s$ electron transfer. In the present study, which of these possible reactive species is present in the reaction is greatly influenced by the ligand. It well known that $N$-alkylation of secondary amine ligands affects the properties of their corresponding metal complexes through the combination of a number of effects such as: (i) decreasing the outer sphere solvation energy of their complexes; (ii) elimination of the $\mathrm{M}-\mathrm{N}-\mathrm{H}^{\cdots} \mathrm{O}$ hydrogen bonds, thus affecting the $\sigma$-donor power of nitrogen; (iii) elongation of $\mathrm{M}-\mathrm{N}$ bonds due to steric hindrance and (iv) making nitrogen a better $\sigma$-donor due to increased electron donation due to hyperconjugation. ${ }^{23}$ In the present case, the oxidation mechanism by which two similar systems 1 and 2 operate appears to be fundamentally different and highlights further how a simple change from N-H to N-Me within a ligand structure alters the overall reactivity. The secondary amine on ligand $\mathbf{7}$ appears to create an active high valent manganese(IV) species, which could be observed by UV-vis spectroscopy and is nucleophilic in nature. In contrast, the coordination of $\mathbf{8}$ results in a manganese centre which is easier to oxidise and which appears to form a reactive intermediate with electron rich styrenes that is electrophilic in nature. However, for electron deficient styrenes our observations of non-linearity in the Hammet plot appears to signify a change in the rate determining step and presumably the nature of the reactive intermediate. 


\section{Conclusion}

We have synthesised chiral ligands and prepared their manganese(II) complexes, which showed efficacy in the epoxidation of styrenes using either hydrogen peroxide or peracetic acid as the oxidant. Despite the inclusion of trans-diaminocyclohexane in the ligand backbone, no asymmetric induction was observed in the final products. Nonetheless, some interesting mechanistic observations were made, which reveal that small changes in ligand architectures from 7 to 8 can induce profound changes in both reactivity and the nature of the active oxidant.

\section{Acknowledgments}

We are grateful to the EPSRC for financial support to GI (EP/H034838/1) and for the provision of the National Mass Spectrometry Service, University of Wales, Swansea. We are also grateful to Dr Aleksandra Pinczewska for assistance with the cyclic voltammetry.

\section{Experimental:}

All reagents were purchased from Aldrich, Acros, Merck or Fluka and were used without further purification unless otherwise stated. The hydrogen peroxide used in the epoxidation procedures was bought from Sigma Aldrich as a 30\% solution in water. Acetonitrile was refluxed over $\mathrm{CaH}_{2}$ for minimum of $6 \mathrm{~h}$ and distilled prior to use. All other solvents that were required to be anhydrous were obtained from solvent purifying system MBRAUN MB SPS800. All water was obtained from an Elga Purelab Option distillation system. ${ }^{1} \mathrm{H}-\mathrm{NMR}$ and ${ }^{13} \mathrm{C}-$ NMR spectra were recorded on a $400 \mathrm{MHz}$ and at $100.2 \mathrm{MHz}$ on a Bruker AV400 or a Bruker AMX400 and referenced to the signal of tetramethylsilane (TMS) or residual protic solvent. IR spectra were recorded on a Perkin Elmer Spectrum 65 IR spectrometer equipped with ATR accessory unless otherwise stated. UV-Vis spectra were obtained on a HP 8453 spectrophotometer, absorption maxima $\left(\lambda_{\max }\right)$ are expressed in $\mathrm{nm}$, the molar extinction coefficients $(\varepsilon)$ are expressed in $\mathrm{L} \mathrm{mol}^{-1} \mathrm{~cm}^{-1}$. Electrospray ionisation mass spectrometry was obtained from the EPSRC National Mass Spectrometry Service, University of Wales, Swansea on a Thermofisher LTQ Orbitrap XL. Cyclic voltammetry was performed on an EG\&G instruments Versastat II workstation, using tetrabutylammonium hexaphosphate as the support electrolyte, a platinum working electrode, a graphite counter electrode and a silver reference electrode in MeCN. Melting points were measured on a Stuart SMP3 melting point apparatus and are uncorrected. High Performance Liquid Chromatography was performed on a Perkin Elmer Series 200 instrument equipped with UV-Vis detector using an Eclips C18 reverse phase 
column and Chiralcel OJ or Chirlacel OD normal phase chiral columns. The calibration procedures and curves, together with selected data and synthesis of styrenes and corresponding epoxides are provided in the ESI.

Resolution of 1,2-diaminocyclohexane was carried out according to previously reported procedure. $^{24}$ Compounds $\mathbf{1 0}$ and $\mathbf{1 1}$ were synthesised according to previously reported procedures. $^{25}$ 4-Nitrostyrene and 4-nitrilestyrene were prepared according to a modified procedure.$^{26}$ PAA was prepared according to previously reported procedure. ${ }^{8 \mathrm{a}-\mathrm{c}}$

\section{$(1 R, 2 R)-N^{1}, N^{1}, N^{2}$-tris(Pyridin-2-ylmethyl)cyclohexane-1,2-diamine 7. ${ }^{9}$}

$\mathrm{NaBH}_{3}(\mathrm{CN})(0.620 \mathrm{~g}, 19.4 \mathrm{mmol}, 2.00$ equiv. $)$ was added portion wise to a solution of $(\boldsymbol{R}, \boldsymbol{R})$ $11(2.00 \mathrm{~g}, 5.19 \mathrm{mmol})$ in dry $\mathrm{MeOH}(100 \mathrm{~mL})$ under atmosphere of nitrogen. This was followed by a drop-wise addition of trifluoroacetic acid ( $0.800 \mathrm{~mL}, 10.4 \mathrm{mmol}, 2.00$ equiv.) and reaction was allowed to stir at r.t. for $16 \mathrm{~h}$. $\mathrm{NaOH}$ (aq. $20 \% \mathrm{w} / \mathrm{v} ; 30 \mathrm{~mL}$ ) was then added to the reaction mixture very slowly and the mixture was extracted with DCM (3 x $100 \mathrm{~mL})$. The combined organic phases were washed with brine $(100 \mathrm{~mL})$, dried over $\mathrm{MgSO}_{4}$ and concentrated in vacuo to give $7(1.98 \mathrm{~g}, 99 \%)$ as a yellow oil: $[\alpha]^{25}{ }_{\mathrm{D}}=-29.8\left(\mathrm{c}=0.66, \mathrm{CHCl}_{3}\right)$, (an identical procedure was followed for ent-7 $(1 S, 2 S)$ isomer $[\alpha]_{\mathrm{D}}^{25}=29.2\left(\mathrm{c}=1, \mathrm{CHCl}_{3}\right)$ ). $(1 R, 2 R)$ isomer; IR (neat, $\left.\nu_{\max } / \mathrm{cm}^{-1}\right): 3049,3006,2927,2855,1590,1568,1473,1432,755$; ${ }^{1} \mathrm{H}-\mathrm{NMR}\left(400 \mathrm{MHz}, \delta-\mathrm{CDCl}_{3}\right)$ : 0.84-1.31 (4H,m, $\left.\mathrm{CH}_{2} \mathrm{CH}_{2} \mathrm{CHN}, \mathrm{CH}_{2} \mathrm{CH}_{2} \mathrm{CHN}\right)$, 1.46-1.59 $\left(1 \mathrm{H}, \mathrm{m}, \mathrm{CH}_{2} \mathrm{CH}_{2} \mathrm{CHN}\right), 1.61-1.75\left(1 \mathrm{H}, \mathrm{m}, \mathrm{CH}_{2} \mathrm{CH}_{2} \mathrm{CHN}\right), 1.95-2.11\left(2 \mathrm{H}, \mathrm{m}, \mathrm{CH}_{2} \mathrm{CH}_{2} \mathrm{CHN}_{\text {, }}\right.$ $\left.\mathrm{CH}_{2} \mathrm{CH}_{2} \mathrm{CHN}\right), 2.34-2.52\left(2 \mathrm{H}, \mathrm{m}, \mathrm{CH}_{2} \mathrm{CH}_{2} \mathrm{CHN}\right), 3.67\left(3 \mathrm{H}, \mathrm{d}, J_{l}=13.9 \mathrm{~Hz}, \mathrm{NCH}_{2} \mathrm{Py}\right), 3.77$ $\left(2 \mathrm{H}, \mathrm{d}, J_{l}=14.2 \mathrm{~Hz}, \mathrm{NCH}_{2} \mathrm{Py}\right), 3.89\left(1 \mathrm{H}, \mathrm{d}, J_{l}=13.9 \mathrm{~Hz}, \mathrm{NCH}_{2} \mathrm{Py}\right), 4.00(1 \mathrm{H}$, broad s, NH) 6.92-7-03 (3H, m, CHPy), 7.17 (1H, d, $\left.J_{1}=7.6 \mathrm{~Hz}, \mathrm{CHPy}\right), 7.41-7.52$ (5H, m, СHРy), 8.308.35 (3H, m, CHPy); ${ }^{13} \mathrm{C}-\mathrm{NMR}\left(100.2 \mathrm{MHz}, \delta-\mathrm{CDCl}_{3}\right): 22.9,24.5,25.4,31.5,52.2 .56 .1$, 57.7, 63.9, 121.6, 121.7, 122.1, 123.0, 136.1, 136.3, 148.6, 148.9, 159.8, 160.1; m/z (ESI): 197.8 (5 \%), 311.7 (5), 388.2 (10), 410.2 (100); HRMS (ESI): $\left[\mathrm{C}_{24} \mathrm{H}_{29} \mathrm{~N}_{5}+\mathrm{Na}\right]^{+}$requires 410.2302 found 410.2306 .

\section{$(1 R, 2 R)-N^{1}$-Methyl- $N^{1}, N^{2}, N^{2}$-tris(pyridin-2-ylmethyl)cyclohexane-1,2-diamine 8.}

$(\boldsymbol{R}, \boldsymbol{R})-7$ (1.60 g, $3.90 \mathrm{mmol})$ was dissolved in mixture of formaldehyde (30\% solution in water, $10 \mathrm{~mL})$ and formic acid $(15 \mathrm{~mL})$. The mixture was heated at $85{ }^{\circ} \mathrm{C}$ for $48 \mathrm{~h}$ and cooled to r.t. The mixture was washed with $\mathrm{Et}_{2} \mathrm{O}(50 \mathrm{~mL})$ and the aqueous phase was cooled on ice. The 
mixture was then basified $(\mathrm{pH}=14)$ with $\mathrm{NaOH}(\mathrm{aq}, 40 \% \mathrm{w} / \mathrm{v})$ and $\mathrm{NaCl}$ was added until the solution became saturated. The product was extracted with $\mathrm{Et}_{2} \mathrm{O}(6 \times 30 \mathrm{~mL})$. The combined extracts were dried over $\mathrm{MgSO}_{4}$, and solvent was removed in vacuo. The residue (1.5 g) was re-dissolved in anhydrous $\mathrm{Et}_{2} \mathrm{O}(30 \mathrm{~mL})$ under atmosphere of nitrogen and filtered to remove any insoluble material. The clear yellow solution was then treated with dry $\mathrm{HCl}(2 \mathrm{M}$ ether solution, $1.5 \mathrm{~mL}$ ) and copious amounts of precipitate was formed. The solid was collected, washed with anhydrous $\mathrm{Et}_{2} \mathrm{O}(2 \times 10 \mathrm{~mL})$ and re-dissolved in water. The mixture was then basified $(\mathrm{pH}=14)$ with $\mathrm{NaOH}($ aq. $40 \%$ w/v) and extracted with DCM (3 x $50 \mathrm{~mL})$. The extracts were combined, dried over $\mathrm{MgSO}_{4}$ and solvent was removed in vacuo to give 8 (1.23 $\mathrm{g}, 75 \%)$ as yellow oil; $[\alpha]_{\mathrm{D}}^{25}=-6.6\left(\mathrm{c}=0.5, \mathrm{CHCl}_{3}\right)$, (an identical procedure was used to prepare ent-8 $(1 S, 2 S)$ isomer, $\left.[\alpha]_{\mathrm{D}}^{25}=7.2\left(\mathrm{c}=0.5, \mathrm{CHCl}_{3}\right)\right) .(1 R, 2 R)$ isomer; IR (neat, $v$ $\left.\max / \mathrm{cm}^{-1}\right): 2927,2852,1589,1567,1472,1432,1355,756 ;{ }^{1} \mathrm{H}-\mathrm{NMR}\left(400 \mathrm{MHz}, \delta-\mathrm{CDCl}_{3}\right)$ : 0.94-1.33 (4H, m, $\left.\mathrm{CH}_{2} \mathrm{CH}_{2} \mathrm{CHN}, \quad \mathrm{CH}_{2} \mathrm{CH}_{2} \mathrm{CHN}\right), \quad 1.60-1.70 \quad\left(2 \mathrm{H}, \quad \mathrm{m}, \quad \mathrm{CH}_{2} \mathrm{CH}_{2} \mathrm{CHN}\right.$, $\left.\mathrm{CH}_{2} \mathrm{CH}_{2} \mathrm{CHN}\right), 1.86-1.94\left(1 \mathrm{H}, \mathrm{m}, \mathrm{CH}_{2} \mathrm{CH}_{2} \mathrm{CHN}\right), 2.04\left(3 \mathrm{H}, \mathrm{s}, \mathrm{CH}_{3}\right), 2.08-2.13(1 \mathrm{H}, \mathrm{m}$, $\left.\mathrm{CH}_{2} \mathrm{CH}_{2} \mathrm{CHN}\right), 2.56\left(1 \mathrm{H}, \mathrm{dt}, J_{1}=11.0 \mathrm{~Hz}, J_{2}=3.5 \mathrm{~Hz}, \mathrm{CH}_{2} \mathrm{CH}_{2} \mathrm{CHN}\right), 2.71\left(1 \mathrm{H}, \mathrm{dt}, J_{l}=10.5\right.$ $\left.\mathrm{Hz}, J_{2}=3.2 \mathrm{~Hz}, \mathrm{CH}_{2} \mathrm{CH}_{2} \mathrm{CHN}\right), 3.68\left(2 \mathrm{H}, \mathrm{d}, J_{l}=2.2 \mathrm{~Hz}, \mathrm{NCH}_{2} \mathrm{Py}\right), 3.81\left(2 \mathrm{H}, \mathrm{d}, J_{l}=14.7 \mathrm{~Hz}\right.$, $\left.\mathrm{NCH}_{2} \mathrm{Py}\right), 4.01\left(2 \mathrm{H}, \mathrm{d}, J_{1}=14.7 \mathrm{~Hz}, \mathrm{NCH}_{2} \mathrm{Py}\right), 6.96-7.09$ (3H, m, CHPy), 7.41-7.50 (4H, m, CHPy), 7.53 (2H, d, $\left.J_{l}=7.8 \mathrm{~Hz}, \mathrm{CHPy}\right), 8.35-8.44$ (3H, m, CHPy); ${ }^{13} \mathrm{C}-\mathrm{NMR}(100.2 \mathrm{MHz}, \delta$ $\left.\mathrm{CDCl}_{3}\right): 23.8,25.6,25.9,27.8,36.2,56.5,60.0,61.0,65.4,121.60,121.67,123.1,123.2,136.0$, 136.2, 148.5, 148.6, 160.6, 161.3; m/z (ESI): 203.1 (15\%), 280.1 (5), 402.2 (100); HRMS (ESI): $\left[\mathrm{C}_{25} \mathrm{H}_{31} \mathrm{~N}_{5}+\mathrm{H}\right]^{+}$requires 402.2657 found 402.2655 .

\section{General procedure for the synthesis of manganese(II) complexes}

The relevant manganese salt (1.0 equiv.) and ligand (1.0 equiv.) were dissolved in acetonitrile $(10 \mathrm{~mL})$. The reaction mixture was heated at reflux for $24 \mathrm{~h}$. After cooling to room temperature diethyl ether was added to the mixture until copious amounts of precipitate was formed, which was collected by filtration. In some cases a thick oil formed from which the solvent was decanted and the oil re-dissolved in DCM $(5 \mathrm{~mL})$. The resultant solution was filtered through celite and the solvent was removed in vacuo to give the product.

$\left[(1 R, 2 R)-N^{1}, \quad N^{1}, \quad N^{2}\right.$-tris(Pyridin-2-ylmethyl)cyclohexane-1,2-diamino]manganese(II) sulfate: an off white solid, 59\%: m.p. $>220{ }^{\circ} \mathrm{C} ;[\alpha]^{25} \mathrm{D}=88.7$ (c $=0.1$, chloroform), $\mu_{\mathrm{eff}}=5.84$ $\mu_{B}$; IR (neat, $v_{\max } / \mathrm{cm}^{-1}$ ): 2934, 2856, 1668, 1637, 1594, 1570, 1476, 1433, 1372, 1278, 1258, 
1151, 1120, 1094, 1050, 999, 875, 765, 751, 637; m/z (ESI): 449 (100\%), 441 (35), 424 (25), 366 (10); HRMS (ESI): $\mathrm{C}_{24} \mathrm{H}_{28} \mathrm{MnN}_{5}$, requires 442.1749 found442.1736; $\lambda_{\max }(\mathrm{DCM}) / \mathrm{nm}(\varepsilon$ $\left./ \mathrm{dm}^{3} \mathrm{~mol}^{-1} \mathrm{~cm}^{-1}\right) 258\left(10.5 \times 10^{3}\right), 263\left(10.9 \times 10^{3}\right), 268\left(9.30 \times 10^{3}\right), 322\left(1.07 \times 10^{3}\right)$.

$\left[(1 R, 2 R)-N^{1}, \quad N^{1}, \quad N^{2}\right.$-tris(Pyridin-2-ylmethyl)cyclohexane-1,2-diamino]manganese(II) chloride: an off white solid, 91\%: m.p. $>220^{\circ} \mathrm{C} ;[\alpha]_{\mathrm{D}}^{25}=134.8\left(\mathrm{c}=0.1\right.$, chloroform); $\mu_{\mathrm{eff}}=$ $5.89 \mu_{\mathrm{B}}$; IR (neat, $v_{\max } / \mathrm{cm}^{-1}$ ): 3050, 2932, 2959, 2414, 1647, 1603,1590, 1569, 1474, 1434, 1265, 1150, 1081, 995, 760, 729, 698, 637, 620; m/z (ESI) 477 (100\%), 388 (45), 297 (45), 221 (17), 181 (12); HRMS (ESI): $\mathrm{C}_{24} \mathrm{H}_{29} \mathrm{MnN}_{5} \mathrm{Cl}$ requires 477.1486 found $477.1484 ; \lambda_{\max }$ $(\mathrm{DCM}) / \mathrm{nm}\left(\varepsilon / \mathrm{dm}^{3} \mathrm{~mol}^{-1} \mathrm{~cm}^{-1}\right) 259\left(9.47 \times 10^{3}\right), 263\left(10.0 \times 10^{3}\right), 269\left(7.08 \times 10^{3}\right)$. Dissolution of the solid in a mixture of MeCN/DCM followed by slow evaporation yieded crystals suitable for single crystal X-ray diffraction. $\mathrm{C}_{24} \mathrm{H}_{31} \mathrm{~N}_{5} \mathrm{OCl}_{2} \mathrm{Mn}, M=531.38$, monoclinic, a $=9.5670(9)$ $\AA, b=15.0540(15) \AA, c=9.7671(13) \AA, \beta=119.292(2)^{\circ}, V=1226.8(2) \AA^{3}$, space group P1 $2_{1}$ $1, \mathrm{Z}=2, \mathrm{~T}=100 .(2) \mathrm{K}, \mathrm{m}=0.783 \mathrm{~mm}-1, \operatorname{MoK} \alpha(\lambda=0.71073 \AA$ ), reflections collected 5802 , independent reflections 5174, final $\mathrm{R}$ indices $[\mathrm{I}>2 \sigma \mathrm{I}] \mathrm{R}_{1}=0.0392 ; \mathrm{wR}_{2}=0.0545$ (all data) $\mathrm{R}_{1}$ $=0.0309, \mathrm{wR}_{2}=0.0524$. Data have been deposited at the Cambridge Crystallographic Database CCDC967858.

$\left[(1 R, 2 R)-N^{1}, \quad N^{1}, \quad N^{2}\right.$-tris(Pyridin-2-ylmethyl)cyclohexane-1,2-diamino]manganese(II) triflate: an off white solid, $85 \%$; m.p. $>220{ }^{\circ} \mathrm{C} ;[\alpha]_{\mathrm{D}}^{25}=84.4(\mathrm{c}=0.1$, chloroform $) ; \mu_{\mathrm{eff}}=5.85$ $\mu_{\mathrm{B}}$; IR (neat, $v_{\max } / \mathrm{cm}^{-1}$ ): 2937, 1606, 1527, 1485, 1443, 1275, 1258, 1238, 1157, 1100, 1080, 1055, 1029, 930, 763, 636, 574; m/z (ESI) 402 (3\%), 442 (25), 591 (100); HRMS (ESI): $\mathrm{C}_{24} \mathrm{H}_{28} \mathrm{MnN}_{5}$ requires 441.1720 found $441.1720 ; \lambda_{\max }(\mathrm{DCM}) / \mathrm{nm}\left(\varepsilon / \mathrm{dm}^{3} \mathrm{~mol}^{-1} \mathrm{~cm}^{-1}\right) 259(13.7 \mathrm{x}$ $\left.10^{3}\right), 263\left(14.3 \times 10^{3}\right), 269\left(10.5 \times 10^{3}\right), 301\left(1.11 \times 10^{3}\right)$.

$\left[(1 R, 2 R)-N^{1}, \quad N^{1}, \quad N^{2}\right.$-tris(Pyridin-2-ylmethyl)cyclohexane-1,2-diamino]manganese(II) acetate: a brown solid, 79\%; m.p. $>220{ }^{\circ} \mathrm{C} ;[\alpha]^{25}{ }_{\mathrm{D}}=(\mathrm{c}=0.1$, chloroform $) ; \mu_{\mathrm{eff}}=5.86 \mu_{\mathrm{B}}$; IR (neat, $v_{\max } / \mathrm{cm}^{-1}$ ): 3211, 2936, 2859, 1634 (v. broad), 1604, 1566, 1479, 1437, 1376, 1308, 1261, 1154, 1097, 1083, 1053, 1013, 996, 933, 879, 842, 764, 701, 637; m/z (ESI) 501 (100\%, [M $\left.\left.\mathrm{CH}_{3} \mathrm{CO}_{2}\right]^{+}\right), 441\left(15,\left[\mathrm{M}-\left(\mathrm{CH}_{3} \mathrm{CO}_{2}\right)_{2}-\mathrm{H}\right]+\right), 366$ (15), 348 (5); HRMS (ESI): $\mathrm{C}_{24} \mathrm{H}_{28} \mathrm{MnN}_{5}$ requires 441.1720 found $441.1719 ; \lambda_{\max }(\mathrm{DCM}) / \mathrm{nm}\left(\varepsilon / \mathrm{dm}^{3} \mathrm{~mol}^{-1} \mathrm{~cm}^{-1}\right) 259\left(13.1 \times 10^{3}\right), 263$ $\left(13.6 \times 10^{3}\right), 269\left(11.0 \times 10^{3}\right), 296\left(2.46 \times 10^{3}\right)$. 
$\left[(1 R, 2 R)-N^{1}, \quad N^{1}, \quad N^{2}\right.$-tris(Pyridin-2-ylmethyl)cyclohexane-1,2-diamino]manganese(II) perchlorate: a pale pink solid, $82 \%$; m.p. $>220{ }^{\circ} \mathrm{C} ;[\alpha]^{25}=-5.4(\mathrm{c}=0.1$, chloroform $) ; \mu_{\mathrm{eff}}=$ $5.88 \mu_{\mathrm{B}}$; IR (neat, $\nu_{\max } / \mathrm{cm}^{-1}$ ): 2931, 2860, 1726, 1605, 1571, 1484, 1441, 1262, 1155, 1086, 1016, 969, 930, 763, 734, 701, 622; m/z (ESI) $541\left(100 \%,\left[\mathrm{M}-\mathrm{ClO}_{4}\right]^{+}\right) ; 501\left(20\right.$, [M - $\left(\mathrm{ClO}_{4}\right)_{2}-$ $\left.\left.\mathrm{H}+\mathrm{CH}_{3} \mathrm{CO}_{2}\right]^{+}\right), 477(60), 441\left(20,\left[\mathrm{M}-\left(\mathrm{ClO}_{4}\right)_{2}\right]^{+}\right), 402$ (25), 384 (30), 366 (25), 294 (15), 221

(75); HRMS (ESI): $\mathrm{C}_{24} \mathrm{H}_{29} \mathrm{MnN}_{5} \mathrm{O}_{4} \mathrm{Cl}$ requires 541.1289 found $541.1276 ; \lambda_{\max }(\mathrm{DCM}) / \mathrm{nm}(\varepsilon$ $\left./ \mathrm{dm}^{3} \mathrm{~mol}^{-1} \mathrm{~cm}^{-1}\right) 258\left(10.4 \times 10^{3}\right), 263\left(10.9 \times 10^{3}\right), 269\left(8.46 \times 10^{3}\right), 302\left(1.44 \times 10^{3}\right)$.

\section{$\left[(1 R, \quad 2 R)-N^{1}-\right.$ Methyl- $N^{1}, \quad N^{2}, \quad N^{2}$-tris(pyridin-2-ylmethyl)cyclohexane-1,2-} diamino]manganese(II) chloride: a light-yellow solid, 82\%: m.p. $>220{ }^{\circ} \mathrm{C} ;[\alpha]^{25}=79.7(\mathrm{c}=$ 0.1 , chloroform); $\mu_{\text {eff }}=5.90 \mu_{\mathrm{B}}$; IR (neat, $v_{\max } / \mathrm{cm}^{-1}$ ): 2932, 2859, 1663, 1604, 1570, 1479, $1441,1306,1260,1155,1098,1052,1015,870,765,638,578 ; \mathrm{m} / \mathrm{z}(\mathrm{ESI}) 491$ (100\%, [M $\mathrm{Cl}^{+}$), 414 (20), 339 (10), 228 (15); HRMS (ESI): $\mathrm{C}_{25} \mathrm{H}_{31} \mathrm{MnN}_{5} \mathrm{Cl}$ requires 491.1643 found $491.1636 ; \lambda_{\max }(\mathrm{DCM}) / \mathrm{nm}\left(\varepsilon / \mathrm{dm}^{3} \mathrm{~mol}^{-1} \mathrm{~cm}^{-1}\right) 258\left(8.41 \times 10^{3}\right), 263\left(7.65 \times 10^{3}\right), 269(5.88 \times$ $\left.10^{3}\right), 325\left(0.656 \times 10^{3}\right)$.

$\left[(1 R, \quad 2 R)-N^{1}-\right.$ Methyl- $N^{1}, \quad N^{2}, \quad N^{2}$-tris(pyridin-2-ylmethyl)cyclohexane-1,2diamino]manganese(II) triflate: a light-yellow solid, 38\%; m.p. $>220{ }^{\circ} \mathrm{C} ;[\alpha]_{\mathrm{D}}^{25}=10.6(\mathrm{c}=$ 0.1, chloroform); $\mu_{\text {eff }}=5.85 \mu_{\mathrm{B}} ;$ IR (neat, $\nu_{\max } / \mathrm{cm}^{-1}$ ): 2938, 2857, 1661, 1607, 1573, 1484,n1445, 1275, 1260, 1238, 1223, 1158, 1029, 949, 764, 637, 574; m/z (ESI) 605 (100\%, $\left.\left[\mathrm{M}-\left(\mathrm{CF}_{3} \mathrm{SO}_{3}\right)\right]\right), 528(7), 491\left(25,\left[\mathrm{M}-\left(\mathrm{CF}_{3} \mathrm{SO}_{3}\right)_{2}+\mathrm{H}_{2} \mathrm{O}+\mathrm{OH}\right]^{+}\right) ;$HRMS (ESI): $\mathrm{C}_{25} \mathrm{H}_{31} \mathrm{~F}_{3} \mathrm{MnN}_{5} \mathrm{O}_{3} \mathrm{~S}$ requires 605.1480 found $605.1464 ; \lambda_{\max }(\mathrm{DCM}) / \mathrm{nm}\left(\varepsilon / \mathrm{dm}^{3} \mathrm{~mol}^{-1} \mathrm{~cm}^{-1}\right) 258$ $\left(9.45 \times 10^{3}\right), 263\left(9.77 \times 10^{3}\right), 269\left(6.86 \times 10^{3}\right)$.

General epoxidation procedure using ligand 7 and $\mathrm{H}_{2} \mathrm{O}_{2}$. A solution of ligand 1 (1.0 mol\%) in $\mathrm{MeCN}(1.0 \mathrm{~mL})$ was delivered to a capped vial containing $\mathrm{MnSO}_{4} \cdot \mathrm{H}_{2} \mathrm{O}(1.0 \mathrm{~mol} \%)$ and the mixture was allowed to stir at r.t. for $30 \mathrm{~min}$. Solutions of styrene in $\mathrm{MeCN}(0.50 \mathrm{M}, 1000 \mu \mathrm{L}$, 1.0 equiv.) and anisole $(0.10 \mathrm{M}, 500 \mu \mathrm{L}$, see note 1) were then delivered to the reaction vial and mixture allowed to equilibrate for $15 \mathrm{~min}$ at room temperature. A solution of $\mathrm{H}_{2} \mathrm{O}_{2}(30 \%$ aq. $855 \mu \mathrm{L}, 10$ equiv.) in acetone $(2500 \mu \mathrm{L})$ was then added to the reaction in one portion and aliquots $(50 \mu \mathrm{L}$ each) were sampled at specific time intervals starting from the addition of peroxide. The aliquots were filtered through a short pad of silica and $\mathrm{MgSO}_{4}$ using $\mathrm{THF}$ as eluent to remove residual $\mathrm{H}_{2} \mathrm{O}$, peroxides and manganese-salts. The aliquots were then 
analysed using HPLC and reaction profiles, yields, conversions and ee were recorded as appropriate.

\section{Epoxidation procedure using ligand 8 and peracetic acid.}

A solution of ligand $2(1.0 \mathrm{~mol} \%)$ in $\mathrm{MeCN}(1.0 \mathrm{~mL})$ was delivered to a capped vial containing $\mathrm{Mn}(\mathrm{OTf})_{2}(1.0 \mathrm{~mol} \%)$ and the mixture was allowed to stir at r.t. for $15 \mathrm{~min}$. Solutions of styrene in $\mathrm{MeCN}(0.50 \mathrm{M}, 1000 \mu \mathrm{L}, 1.0$ equiv.) and anisole $(0.10 \mathrm{M}, 500 \mu \mathrm{L}$, note 1) were then delivered to the reaction vial followed by the addition of $\mathrm{MeCN}(2500 \mu \mathrm{L})$ and mixture allowed to equilibrate for $15 \mathrm{~min}$ at room temperature. The reaction mixture was then cooled on ice and PAA (1.2 equiv.) was added in one portion. The aliquots (50 $\mu \mathrm{L}$ each) were sampled at specific time intervals starting from the addition of oxidant. The aliquots were filtered through a short pad of silica and $\mathrm{MgSO}_{4}$ using THF as eluent to remove residual PAA and Mn-salts. The aliquots were then analysed using HPLC and reaction profiles, yields, conversions and e.e. were recorded as appropriate.

Note 1: An equivalent amount of 1,2-dichlorobenzene was used as internal standard during the epoxidation of 4-nitrilestyrene due to the overlap of signals on HPLC trace.

\section{References.}

1. (a) R. G. Bergman, Nature, 2007, 446, 391-393; (b) P. Saisaha, J. W. de Boer and W. R. Browne, Chem. Soc. Rev., 2013, 42, 2059-2074; (c) E. P. Talsi and K. P. Bryliakov, Coord. Chem. Rev., 2012, 256, 1418-1434; (d) D. J. Covell and M. C. White, Angew. Chem. Int. Ed., 2008, 47, 6448-6451.

2. (a) I. W. C. E. Arends, Angew. Chem., Int. Ed., 2006, 45, 6250-6252; (b) P. Saisaha, J.W. de Boer and W.R. Browne, Chem. Soc.Rev., 2013, 42, 2059-2074; (c) G. Shul'pin, Dalton Trans., 2013, 42, 12794-12818.

3. (a) T. Katsuki and K. B. Sharpless, J. Am. Chem. Soc., 1980, 102, 5974-5976; (b) R. A. Johnson and K. B. Sharpless, Catalytic Asymmetric Synthesis, Ed: I. Ojima, VCH, New York, 1993, chap. 4.1.

4. (a) W. Zhang, J. L. Leobach, S. R. Wilson and E. N. Jacobsen, J. Am. Chem. Soc., 1990, 112, 2801-2803; (b) E. N. Jacobsen, Catalytic Asymmetric Synthesis, Ed: I. Ojima, VCH, New York, 1993, chap. 4.2.

5. (a) R. Irie, K. Noda, Y. Ito, N. Matsumoto and T. Katsuki, Tetrahedron Lett., 1990, 31, 7345-7348; (b) T. Katsuki, Coord. Chem. Rev., 1995, 140, 189-214; (c) T. Katsuki, Adv. Synth. Catal., 2002, 344, 131-147. 
6. for example: (a) M. Shibasaki, M. Kanai, S. Matsunaga and N. Kumagai, Acc. Chem. Res., 2009, 42, 1117-1127; (b) G. D. Faveri, G. Ilyashenko and M. Watkinson, Chem. Soc. Rev., 2011, 40, 1722-1760.

7. H. Doucet, T. Ohkuma, K. Murata, T. Yokozawa, M. Kozawa, E. Katayama, A. F. England, T. Ikariya, R. Noyori, Angew. Chem. Int. Ed., 1998, 37, 1703-1707.

8. (a) A. Murphy, G. Dubois and T. D. P. Stack, J. Am. Chem. Soc., 2003, 125, 5250-5251; (b) A. Murphy, A. Pace and T. D. P. Stack, Org. Lett., 2004, 6, 3119-3122; (c) A. Murphy and T. D. P. Stack, J. Mol. Catal. A: Chem., 2006, 251, 78-88; (d) L. Gomez, I. Garcia-Bosch, A. Company, X. Sala, X. Fontrodona, X. Ribas and M. Costas, Dalton Trans., 2007, 5539-5545; (e) M. Wu, B. Wang, S. F. Wang, C. G. Xia and W. Sun, Org. Lett., 2009, 11, 3622-3625; (f) X. Wu, M. S. Seo, K. M. Davis, Y.-M. Lee, J. Chen, K.-B. Cho, Y. N. Pushkar,, and W. Nam, J. Am. Chem. Soc., 2011, 133, 20088-20091; (g) T. W.-S. Chow, Y. Liu and C.-M. Che, Chem. Commun., 2011, 47, 11204-11206; (h) L. Gomez, I. Garcia-Bosch, A. Company, J. BenetBuchholz, A. Polo, X. Sala, X. Ribas and M. Costas, Angew. Chem., Int. Ed., 2009, 48, 57205723; (i) G. Ilyashenko, D. Sale, M. Motevalli and M. Watkinson, J. Mol. Catal. A: Chem., 2008, 296, 1-8; (j) O. Cussó, I. Garcia-Bosch, X. Ribas, J. Lloret-Fillol and M. Costas, J. Am. Chem. Soc., 2013, 135, 14871-14878.

9. M. M. Hammoud, J. J. McKamie, M. J. Heeg and J. J. Kodanko, Dalton Trans., 2008, 4843-4845.

10. G. Ilyashenko, G. D. Faveri, S. Masoudi, R. Al-Safadi and M. Watkinson, Org. Biomol. Chem., 2013, 11, 1942-1951.

11. K. Matsumoto, Y. Sawada, B. Saito, K. Sakai and T. Katsuki, Angew. Chem., Int. Ed., 2005, 44, 4935-4939.

12. D. Pijper, P. Saisaha, J. W. de Boer, R. Hoen, C. Smit, A. Meetsma, R. Hage, R. P. van Summeren, P. L. Alsters, B. L. Feringa, and W. R. Browne, Dalton Trans., 2010, $10375-10381$.

13. D. F. Evans, J. Chem. Soc. 1959, 2003-2005.

14. a) G. Chelucci, Coord. Chem. Rev., 2013, 257, 1887-1932; b) R. Hage, Recl. Trav. Chim. Pays Bas, 1996 , 115 , 385-195; J. Glerup, P.A. Goodson, D.J. Hodgson, K. Michelsen, K.M. Nielsen, and H. Weihe, Inorg. Chem., 1992, 31, 4611-4616.

15. J. J. Blumenstein, V. C. Ukachukwu, R. S. Mohan and D. L. Whalen, J. Org. Chem., 1993, 58, 924-932.

16. H. E. Audier, J. F. Dupin and J. Jullien, J. Bull. Soc. Chim. Fr., 1968, 9, 3850.

17. (a) L. P. Hammett, J. Am. Chem. Soc., 1937, 59, 96-103; (b) C. Hansch, A. Leo and R. W. 
Taft, Chem. Rev., 1991, 91, 165-195.

18 (a) P. R. Young and W. P. Jencks, J. Am. Chem. Soc., 1979, 101, 3288-3294; (b) A. R. Stein, M. Tencer, E. A. Moffatt, R. Dawe and J. Sweet, J. Org. Chem., 1980, 45, 3539-3540.

19. (a) S. C. Sawant, X. Wu, J. Cho, K.-B. Cho, S. H. Kim, M. S. Seo, Y.-M. Lee, M. Kubo, T. Ogura, S. Shaik, W. Nam, Angew. Chem. Int. Ed., 2010, 49, 8190 -8194; (b) T. H. Parsell, R. K. Behan, M. T. Green, M. P. Hendrich and A. S. Borovik, J. Am. Chem. Soc., 2006, 128, 8728-8729; (c) I. Garcia-Bosch, A. Company, C. W. Cady, S. Styring, W. R. Browne, X. Ribas and M. Costas, Angew. Chem. Int. Ed., 2011, 50, 5648-5653.

20. X. Wu, M. S. Seo, K. M. Davis, Y.-M. Lee, J. Chen, K.-B. Cho, Y. N. Pushkar, and W Nam, J. Am. Chem. Soc., 2011, 133, 20088-20091.

21. T. J. Hubin, J. M. McCormick, S. R. Collinson, M. Buchalova, C. M. Perkins, N. W. Alcock, P. M. Kahol, A. Raghunathan and D. H. Busch, J. Am. Chem. Soc., 2000, 122, 25122522.

22. for example: E. M. McGarrigle and D. G. Gilheany, Chem. Rev., 2005, 105, 1565-1602.

23. D. Meyerstein, Coord. Chem. Rev., 1999, 185-186, 141-147.

24. H.-J. Schanz, M. A. Linseis and D. G. Gilheany, Tetrahedron: Asymmetry, 2003, 14, 2763-2769.

25. (a) H.-J. Cristau, P. P. Cellier, S. Hamada, J.-F. Spindler and M. Taillefer, Org. Lett., 2004, 6, 913-916; (b) W. Park, M. H. Shin, J. H. Chung, J. Park, M. S. Lah and D. Lim, Tetrahedron Lett., 2006, 47, 8841-8845.

26. G. A. Molander and A. R. Brown, J. Org. Chem., 2006, 71, 9681-9686. 